\title{
Group B Streptococcal Sepsis in Piglets: Effect of Combined Pentoxifylline and Indomethacin Pretreatment
}

\author{
RONALD L. GIBSON, WILLIAM E. TRUOG, WILLIAM R. HENDERSON, JR., AND \\ GREGORY J. REDDING \\ Departments of Pediatrics and Medicine, University of Washington School of Medicine, \\ Seattle, Washington 98195
}

\begin{abstract}
Group B streptococcus (GBS), a common neonatal gram-positive pathogen, causes similar pathophysiology in human newborns and neonatal animal models of sepsis. Animal models of GBS sepsis demonstrate a two-phase response: 1$)$ an acute phase $(<1 \mathrm{~h})$ of increased pulmonary artery pressure $\left(\mathrm{P}_{\mathrm{pa}}\right)$ and reduced arterial oxygen pressure $\left(\mathrm{PaO}_{2}\right)$ that is associated with increased serum thromboxane $\mathrm{B}_{2}\left(\mathrm{TxB}_{2}\right)$ and 2$)$ a late phase (2-4 h) of persistently increased $\mathrm{P}_{\mathrm{pa}}$ and reduced $\mathrm{PaO}_{2}$, reduced systemic arterial pressure, and progressive fall in cardiac output that is associated with increased serum $\mathrm{TxB}_{2}, 6$ keto-prostaglandin $\mathrm{F}_{1 \alpha}$ (6-keto-PGF $\left.\mathrm{F}_{\alpha}\right)$, and tumor necrosis factor- $\alpha\left(\mathrm{TNF}_{\alpha}\right)$. We hypothesized that pretreatment of piglets with both pentoxifylline (PTF), an inhibitor of $\mathrm{TNF}_{\alpha}$ production and activity, and indomethacin (INDO) would 1) inhibit GBS-induced $\mathrm{TxB}_{2}$, 6-keto-PGF ${ }_{1 \alpha}$, and $\mathrm{TNF}_{\alpha}$ and 2) prevent both the acute- and late-phase physiologic responses of GBS sepsis. Combined PTF and INDO pretreatment of anesthetized, mechanically ventilated piglets infused with GBS $\left(1.25 \times 10^{9}\right.$ colony forming units/ $\mathrm{kg} / \mathrm{h}$ ) for $4 \mathrm{~h}$ prevented GBS-induced increases in $P_{\mathrm{pa}}$ at 1 h (GBS+PTF+INDO: $1.8 \pm 0.07 \mathrm{kPa}$ versus GBS alone: $4.7 \pm 0.1 \mathrm{kPa}$ ) and markedly attenuated increases in $P_{\mathrm{pa}}$ at $4 \mathrm{~h}$ (GBS+PTF+INDO: $2.1 \pm 0.1 \mathrm{kPa}$ versus GBS alone: $4.4 \pm 0.1 \mathrm{kPa}$ ). PTF+INDO treatment prevented GBS-induced reductions in both mixed venous oxygen pressure and $\mathrm{PaO}_{2}$ at 1,2 , and $4 \mathrm{~h}$ (GBS+PTF+INDO: 11.5 $\pm 0.4 \mathrm{kPa}$ versus $\mathrm{GBS}$ alone: $7.1 \pm 0.4 \mathrm{kPa}$ ), and attenuated GBS-induced declines in cardiac output. PTF+INDO treatment significantly attenuated GBS-induced serum $\mathrm{TNF}_{\alpha}$ polypeptide levels (ELISA, $\mathrm{pg} / \mathrm{mL}$ ) at $4 \mathrm{~h}$ (GBS+PTF+INDO: $143 \pm 45$ versus GBS alone: $502 \pm$ 147) and blocked GBS-induced increases in serum $\mathrm{TxB}_{2}$ and 6-keto-PGF ${ }_{1 \alpha}$ (all levels $<10 \mathrm{pg} / 0.1 \mathrm{~mL}$ by RIA). INDO pretreatment alone prevented GBS-induced increases in serum $\mathrm{TxB}_{2}$ and 6-keto-PGF ${ }_{1 \alpha}$ levels but did not significantly inhibit GBS-induced $\mathrm{TNF}_{\alpha}$ production. INDO pretreatment alone did not attenuate GBS-induced increases in Ppa at $4 \mathrm{~h}$, nor prevent late-phase reductions in both $\mathrm{PaO}_{2}$ and mixed venous oxygen pressure. $\mathrm{PTF}+\mathrm{INDO}$ treatment of GBS sepsis in piglets is superior to treatment with INDO or PTF alone. Inhibition of both blood eicosanoid and $\mathrm{TNF}_{\alpha}$ production may provide adjunctive therapy for human newborns with sepsis and pulmonary hypertension. (Pediatr Res 31: 222-227, 1992)
\end{abstract}

Received July 1, 1991; accepted October 17, 1991.

Correspondence: Ronald L. Gibson, M.D., Ph.D., Department of Pediatrics, RD-20, University of Washington School of Medicine, Seattle, WA 98195.

Supported by an RJR Nabisco Pulmonary Research Scholar Award (R.L.G.). Supported in part by NIH Grant HL39157 (W.E.T., W.R.H., and G.J.R.) and NIH Grant HL30542 (W.R.H.).
Abbreviations

cfu, colony forming unit

$\mathrm{CO}$, cardiac output

GBS, group B streptococcus

INDO, indomethacin

$\mathbf{P G I}_{2}$, prostaglandin $\mathrm{I}_{2}$

6-keto-PGF ${ }_{1 \alpha}$, 6-keto-prostaglandin $\mathrm{F}_{1 \alpha}$

$\mathbf{P}_{\mathrm{pa}}$, pulmonary artery pressure

$P_{\text {sa }}$, systemic arterial pressure

PTF, pentoxifylline

PVR, pulmonary vascular resistance

$\mathrm{TNF}_{\alpha}$, tumor necrosis factor- $\alpha$

$\mathrm{TxB}_{2}$, thromboxane $\mathrm{B}_{2}$

$\mathrm{TxA}_{2}$, thromboxane $\mathrm{A}_{2}$

$\mathrm{PaO}_{2}$, arterial oxygen pressure

$P_{w}$, capillary wedge pressure

SVR, systemic vascular resistance

GBS sepsis in human neonates is associated with hypoxemia, pulmonary hypertension, shock, and high mortality (1-3). Neonatal animal models of i.v. GBS infusion show similar features, but with the delineation of both an acute and late phase response $(4,5)$. Acute features $(<1 \mathrm{~h})$ include pulmonary hypertension, hypoxemia, and reduced $\mathrm{CO}$. The acute phase of GBS infusion in animals is associated with increased serum $\mathrm{TxB}_{2}$ levels, a stable metabolite of the potent vasoconstrictor $\operatorname{TxA}_{2}(5,6)$. Inhibition of $\mathrm{TxA}_{2}$ synthesis by indomethacin (INDO), a cyclooxygenase inhibitor, or dazmegrel, a thromboxane synthase inhibitor, prevents the acute pulmonary hypertension and hypoxemia of GBS bacteremia in piglets $(5,6)$. Dimethylthiourea also attenuates GBS-induced acute pulmonary hypertension and hypoxemia in piglets, suggesting that hydroxyl radicals contribute to the acute features of GBS sepsis (7).

The late features (2-4 h) of GBS infusion in animal models include persistent pulmonary hypertension, hypoxemia, progressive fall in $C O$, systemic hypotension, and lung injury (4-6). The late phase of GBS infusion is associated with increased serum levels of $\mathrm{TxB}_{2}, 6$-keto-PGF ${ }_{1 \alpha}$, a stable metabolite of the potent vasodilator $\mathrm{PGI}_{2}$, and $\mathrm{TNF}_{\alpha}(5,6,8,9)$. Early INDO administration blocks the late phase increase in both serum $\mathrm{TxB}_{2}$ and 6 keto-PGF PG $_{1 \alpha}(5)$, but serum $\mathrm{TNF}_{\alpha}$ levels were not measured in these studies. INDO treatment causes little improvement in late phase GBS-induced pulmonary hypertension (5), but partially attenuates late phase GBS-induced systemic hypotension, reduced $\mathrm{CO}$, and hypoxemia (5). PTF, a methylxanthine that inhibits $\mathrm{TNF}_{\alpha}$ production and activity $(10-15)$, significantly reduces GBS-induced serum $\mathrm{TNF}_{\alpha}$ polypeptide levels in neonatal piglets, but does not inhibit GBS-induced $\mathrm{TxA}_{2}$ or $\mathrm{PGI}_{2}$ produc- 
tion (8). However, PTF causes only a mild improvement in GBSinduced late-phase pulmonary hypertension and hypoxemia in piglets (8). These combined observations show that neither treatment with INDO nor PTF alone causes marked improvement in the late phase of GBS infusion in piglets. We speculate that arachidonic acid metabolites and $\mathrm{TNF}_{\alpha}$ may act in an additive or synergistic manner to contribute to the late-phase features of GBS sepsis.

We hypothesized that combined PTF and INDO pretreatment would inhibit GBS-induced $\mathrm{TxA}_{2}, \mathrm{PGI}_{2}$, and $\mathrm{TNF}_{\alpha}$ production and would prevent both the acute and late phase pathophysiologic responses of GBS sepsis in neonatal piglets.

\section{MATERIALS AND METHODS}

Animal preparation. Twenty piglets were anesthetized (30 mg/ $\mathrm{kg}$ pentobarbital i.v.), paralyzed $(0.3 \mathrm{mg} / \mathrm{kg}$ pancuronium bromide i.v.), anticoagulated with heparin (1000 IU i.v.), and mechanically ventilated via a tracheostomy tube with a large animal Harvard ventilator adjusted to deliver a tidal volume of $12 \pm 2$ $\mathrm{mL} / \mathrm{kg}$ at a rate to maintain arterial carbon dioxide pressure at 4.6 to $5.3 \mathrm{kPa}(35-40 \mathrm{~mm} \mathrm{Hg})$ during baseline conditions. The piglets from each experimental group were of similar age and weight: GBS alone, $3.1 \pm 0.5 \mathrm{~kg}, 12 \pm 2 \mathrm{~d}$ of age; GBS+INDO, $3.5 \pm 8 \mathrm{~kg}, 13 \pm 2 \mathrm{~d}$ of age; GBS+PTF+INDO, $3.6 \pm 0.7 \mathrm{~kg}, 12$ $\pm 2 \mathrm{~d}$ of age. All animals were ventilated with room air throughout each experiment. As previously described (16), catheters were placed in 1) the left external jugular vein for infusion of GBS, PTF, or INDO (double lumen 5 Fr Swan-Ganz, American Edwards Laboratories, Irvine, $C A), 2$ ) the aorta to measure $\mathbf{P}_{\mathrm{sa}}$ and sample arterial blood for $\mathrm{pH}$, blood gas tensions, and eicosanoid and $\mathrm{TNF}_{\alpha}$ measurements, and 3) a branch of the left pulmonary artery (5 Fr Swan-Ganz thermodilution catheter) to measure $P_{\mathrm{pa}}$ and $\mathrm{P}_{\mathrm{w}}$ and $\mathrm{CO}$ in triplicate by thermodilution using an Edwards 9520A CO computer (American Edwards Laboratories) and for sampling mixed venous blood. After instrumentation, anesthesia and muscle paralysis were maintained with pentobarbital $(3 \mathrm{mg} /$ $\mathrm{kg}$ i.v. every h) and pancuronium bromide ( $3 \mathrm{mg} / \mathrm{kg}$ i.v. every h), respectively. The piglets received sigh breaths to $30 \mathrm{~cm} \mathrm{H}_{2} \mathrm{O}$ every 20 min to minimize spontaneous development of atelectasis. Vascular pressures were measured using Hewlett-Packard 1280 transducers (Hewlett-Packard Co., Palo Alto, CA) referenced to mid-chest. Core temperature was maintained at $38.5 \pm$ $0.5^{\circ} \mathrm{C}$ with an overhead radiant heat source.

$G B S$ strain and preparation. The GBS strain is a type III clinical isolate made rifampin- and streptomycin-resistant $(\mathrm{COH}$ $31 \mathrm{r} / \mathrm{s}$ ) (16). The culture conditions, mode of resuspension in sterile nonbacteriostatic saline, and tests of culture purity were performed as described (17). The GBS suspensions for infusion into piglets contained $<0.03$ endotoxin units $/ \mathrm{mL}$ of endotoxin based on the limulus amebocyte lysate assay ( 5 endotoxin units/ $\mathrm{mL}=1 \mathrm{ng} / \mathrm{mL}$ ) (Associates of Cape Cod, Woods Hole, MA).

Eicosanoid assays. Two-mL arterial blood samples were obtained under each of the four experimental conditions. The blood samples were drawn into cold inhibitor solution containing indomethacin and sodium EDTA and centrifuged as previously described (9). The decanted plasma was frozen at $-70^{\circ} \mathrm{C}$ until RIA for $\mathrm{TxB}_{2}$ and 6-keto-PGF $\mathrm{PG}_{1 \alpha}$ were performed as described (9). $\mathrm{TxB}_{2}$ and 6 -keto- $\mathrm{PGF}_{1 \alpha}$ were assayed by measuring competitive inhibition of $\left[{ }^{3} \mathrm{H}\right] \mathrm{TxB}_{2}$ to rabbit anti- $\mathrm{TxB}_{2}$ binding or $\left[{ }^{3} \mathrm{H}\right] 6-k e t o-P F_{1 \alpha}$ to anti-6-keto-PGF ${ }_{1 \alpha}$, respectively (9). The average of duplicate assays was used to determine group means for the different experimental conditions. The limit of detection for $\mathrm{TxB}_{2}$ and 6-keto- $\mathrm{PGF}_{1 \alpha}$ was $<10 \mathrm{pg} / 0.1 \mathrm{~mL}$. Matrix effects due to protein present in piglet plasma were measured in standard curves using eicosanoid-free piglet plasma prepared by charcoal stripping (9).

$T N F_{\alpha}$ ELISA assay. Two-mL arterial blood samples were obtained under each of the four experimental conditions for each piglet. The samples were stored on ice during the protocol and then centrifuged at $15000 \mathrm{rpm} \times 15 \mathrm{~min}$. The decanted serum was frozen and stored at $-70^{\circ} \mathrm{C}$ until a $\mathrm{TNF}_{\alpha}$ ELISA assay was performed in duplicate. A human $\mathrm{TNF}_{\alpha}$ serum ELISA kit was kindly provided by Genentech, Inc., San Francisco, CA. This "sandwich" ELISA assay used rabbit anti-TNF $\alpha$ coat antibody (Genentech, Inc., Lot 4701-92) and horseradish peroxidase-con-


4707-25), as described (8). A human recombinant $\mathrm{TNF}_{\alpha}$ (Genentech, Inc., Lot TH151A) standard curve was prepared over the range of 35 to $2000 \mathrm{pg} / \mathrm{mL}$ in PBS containing BSA $(5 \mathrm{mg} / \mathrm{mL})$. A relationship between OD at $490 \mathrm{~nm}$ and $\mathrm{TNF}_{\alpha}$ concentration is derived from the standard curve by linear regression. The piglet serum $\mathrm{TNF}_{\alpha}$ levels were derived by interpolation from the average of the two assays. The limit of $\mathrm{TNF}_{\alpha}$ detection by our assay was $<35 \mathrm{pg} / \mathrm{mL}$.

Experimental design. After instrumentation, each piglet received $10 \mathrm{~mL} / \mathrm{kg} 0.9 \%$ saline i.v. to ensure a standardized euvolemic state. Data from three groups of piglets are reported: Group 1 (GBS alone), in which seven piglets received saline (2 $\mathrm{mL} / \mathrm{kg}$ i.v. bolus, followed by saline infusion at $2 \mathrm{~mL} / \mathrm{kg} / \mathrm{h}$ ) and $30 \mathrm{~min}$ later received i.v. GBS at $1.25 \times 10^{9} \mathrm{cfu} / \mathrm{kg} / \mathrm{h}$ for $4 \mathrm{~h}$; Group 2 (GBS+INDO), in which six piglets received INDO [3 $\mathrm{mg} / \mathrm{kg}$ i.v. bolus $(1 \mathrm{~mL} / \mathrm{kg})$, followed by $0.9 \%$ saline infusion at $2 \mathrm{~mL} / \mathrm{kg} / \mathrm{h}]$ and $30 \mathrm{~min}$ later received i.v. GBS at $1.25 \times 10^{9}$ $\mathrm{cfu} / \mathrm{kg} / \mathrm{h}$ for $4 \mathrm{~h}$; and Group 3 (GBS+PTF+INDO), in which seven piglets received i.v. PTF $(20 \mathrm{mg} / \mathrm{kg}$ i.v. bolus followed by $20 \mathrm{mg} / \mathrm{kg} / \mathrm{h}$ infusion) and INDO (3 mg/ $\mathrm{kg}$ i.v.) and $30 \mathrm{~min}$ later received i.v. GBS at $1.25 \times 10^{9} \mathrm{cfu} / \mathrm{kg} / \mathrm{h}$ for $4 \mathrm{~h}$. Piglets infused with $0.9 \%$ saline or PTF $(20 \mathrm{mg} / \mathrm{kg}$ bolus, then $20 \mathrm{mg} / \mathrm{kg} / \mathrm{h})$ alone showed no significant physiologic abnormalities and no significant increases in $\mathrm{TxB}_{2}, 6$-keto- $\mathrm{PGF}_{1 \alpha}$, or $\mathrm{TNF}_{\alpha}(8)$.

In each piglet, $\mathrm{P}_{\mathrm{pa}}, \mathrm{P}_{\mathrm{w}}, \mathrm{P}_{\mathrm{sa}}, \mathrm{CO}$, arterial and mixed venous blood gas tensions, and arterial blood samples for measurement of $\mathrm{TxB}_{2}$, 6-keto-PGF $\mathrm{P}_{1 \alpha}$, and $\mathrm{TNF}_{\alpha}$ were obtained at baseline (PRE) and at 1, 2, and 4 h. PVR $\left(\mathrm{P}_{\mathrm{pa}}-\mathrm{P}_{\mathrm{w}} / \mathrm{CO}\right)$ and SVR $\left(\mathrm{P}_{\mathrm{sa}} / \mathrm{CO}\right)$ were calculated at the same time points for each piglet.

Statistical analysis. Analysis of variance with Student-Neuman-Keuls correction for multiple comparisons was used to compare values between the experimental groups; paired $t$ tests were used to compare intragroup values (SPSS/PC+ v3.0, SPSS, Inc., Chicago, IL). A $p$ value of $<0.05$ was considered significant.

\section{RESULTS}

Pulmonary hemodynamics. Figures 1 and 2 depict changes in $\mathrm{P}_{\mathrm{pa}}$ and PVR, respectively, during the 4- $\mathrm{h}$ infusions for each group of piglets. INDO pretreatment inhibited GBS-induced

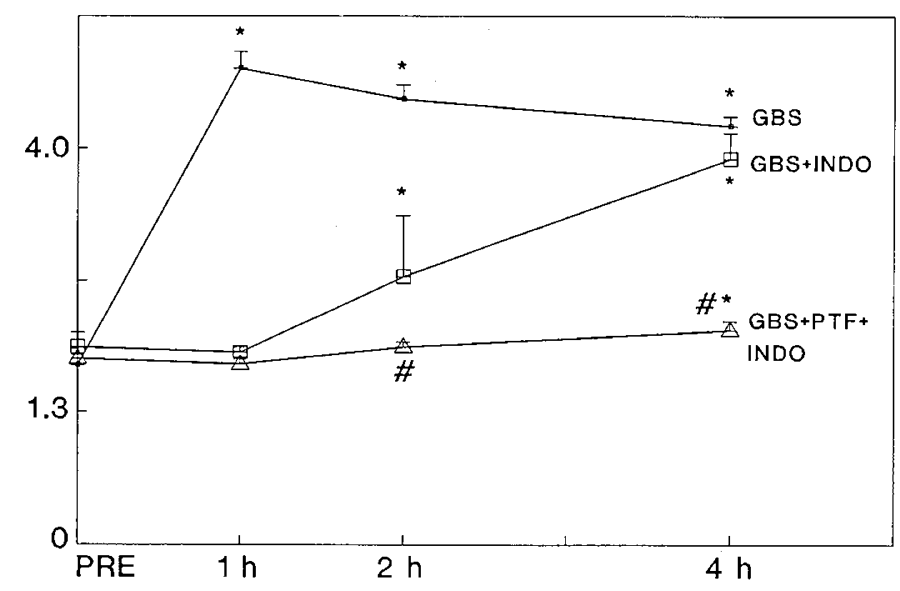

Fig. 1. PTF+INDO attenuates GBS-induced acute- and late-phase increases in $\mathrm{P}_{\mathrm{pa}}$. Mean $\mathrm{P}_{\mathrm{pa}}$ values $(\mathrm{kPa})$ are plotted versus time for the three groups of piglets. Values are expressed as mean $\pm \mathrm{SEM} .{ }^{*}$ denotes $p<0.05$ compared with the intragroup PRE value; \# denotes $p<0.05$ compared with the other two groups at the same time point. 


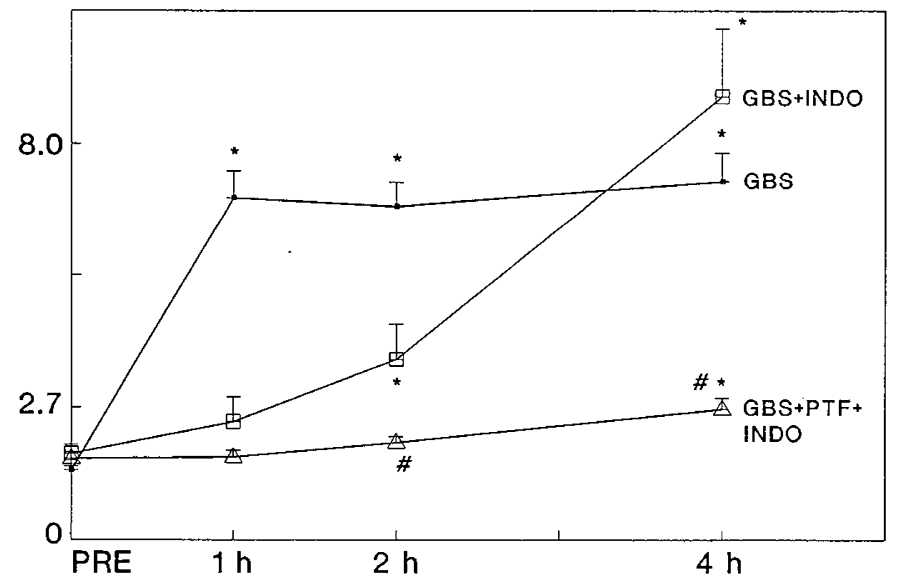

Fig. 2. PTF+INDO attenuates GBS-induced acute- and late-phase increases in PVR. PVR values $(\mathrm{kPa} / \mathrm{L} / \mathrm{min})$ are plotted versus time for the three groups of piglets. Values are expressed as mean \pm SEM. * denotes $p<0.05$ compared with intragroup PRE value; \# denotes $p<$ 0.05 compared with the other two groups at the same time point.

acute increases in $\mathrm{P}_{\mathrm{pa}}$ and $\mathrm{PVR}$, but resulted in no improvement in $P_{p a}$ or PVR at $4 \mathrm{~h}$ in GBS+INDO compared with GBS alone piglets. PTF+INDO pretreatment prevented the GBS-induced acute increases in $\mathrm{P}_{\mathrm{pa}}$ and PVR and markedly attenuated the increase in $\mathrm{P}_{\mathrm{pa}}$ and $\mathrm{PVR}$ at $4 \mathrm{~h}$ compared with the other two groups of piglets $(p<0.05)$.

Systemic hemodynamics. Table 1 shows the changes in $\mathrm{CO}$, $P_{\text {sa }}$, and SVR for each group of piglets during the 4-h infusions. INDO pretreatment did not improve $\mathrm{CO}$ at $1 \mathrm{~h}$ or $4 \mathrm{~h}$ in GBS+INDO compared with GBS alone piglets. PTF+INDO pretreatment prevented the acute fall in $\mathrm{CO}$ and significantly improved CO compared with the other two groups at 1 and $2 \mathrm{~h}$; PTF+INDO pretreatment significantly improved $\mathrm{CO}$ at $4 \mathrm{~h}$ in $\mathrm{GBS}+\mathrm{PTF}+\mathrm{INDO}$ piglets compared with the other two groups $(p<0.05)$.

$P_{\text {sa }}$ was not significantly reduced at 1 and $2 \mathrm{~h}$ of infusion in any of the groups; $P_{\mathrm{sa}}$ was significantly reduced at $4 \mathrm{~h}$ in GBS alone and GBS+PTF+INDO piglets. Piglets infused with GBS+INDO showed no significant fall in $P_{s a}$ at $4 \mathrm{~h}$. INDO treatment, but not combined PTF+INDO treatment, attenuated the GBS-induced decrease in $\mathrm{P}_{\mathrm{sa}}$ at $4 \mathrm{~h}$.

SVR increased significantly from baseline at 1,2 , and $4 \mathrm{~h}$ in GBS alone and at 2 and $4 \mathrm{~h}$ in GBS+INDO piglets; SVR did not significantly change from baseline at 1,2 , or $4 \mathrm{~h}$ in GBS+PTF+INDO piglets (Table 1).

Ratio of pulmonary vascular resistance to systemic vascular resistance. The PVR/SVR ratio was similar at baseline for the three experimental groups (Table 2). The PVR/SVR ratio increased from baseline at 1,2 , and $4 \mathrm{~h}$ in the GBS alone piglets. INDO pretreatment prevented an increase in the PVR/SVR ratio at $1 \mathrm{~h}$, but not at 2 or $4 \mathrm{~h}$, where values were similar to those of GBS alone piglets. PTF+INDO treatment prevented a significant increase in the PVR/SVR ratio at $1 \mathrm{~h}$ and significantly attenuated the increase in PVR/SVR ratio at $4 \mathrm{~h}$ compared with GBS and GBS+INDO piglets.

Gas exchange. Table 3 shows the blood gas values for each group of piglets during the 4-h infusions. INDO treatment prevented the fall in $\mathrm{PaO}_{2}$ at 1 and $2 \mathrm{~h}$, and $\mathrm{PaO}_{2}$ at $4 \mathrm{~h}$ was significantly improved in GBS+INDO compared with GBS alone piglets. However, $\mathrm{PaO}_{2}$ at $4 \mathrm{~h}$ was significantly decreased from baseline values in GBS+INDO piglets. PTF+INDO treatment resulted in no significant decrease in $\mathrm{PaO}_{2}$ at 1,2 , and $4 \mathrm{~h}$. The $\mathrm{PaO}_{2}$ at $4 \mathrm{~h}$ was significantly improved in GBS+PTF+INDO piglets compared with the 4-h $\mathrm{PaO}_{2}$ in the other two groups.

In contrast to the other groups, piglets infused with GBS+PTF+INDO showed no significant decrease in mixed venous oxygen pressure during the 4 - $h$ infusion. All groups showed a statistically significant decrease in arterial $\mathrm{pH}$ by $4 \mathrm{~h}$ of infusion, but INDO and PTF+INDO treatment prevented the development of significant metabolic acidosis ( $\mathrm{pH}<7.35$ ). The calculated base excess at baseline was similar for the three groups (GBS: $2 \pm 0.8$, GBS+INDO: $2 \pm 1.1$, GBS+PTF+INDO: $1.5 \pm$ $0.9)$. However, both INDO and PTF+INDO treatment attenuated the GBS-induced decline in base excess at $4 \mathrm{~h}$ (GBS: $7 \pm$ 1.1, GBS+INDO: $-1.8 \pm 1.1$, GBS+PTF+INDO: $-0.5 \pm 0.8$ ).

Eicosanoids. Figures $3 \mathrm{~A}$ and $3 \mathrm{~B}$ depict changes in serum $\mathrm{TxB}_{2}$ and 6-keto-PGF ${ }_{1 \alpha}$ levels, respectively, for each group of piglets. INDO and PTF+INDO treatment prevented GBS-induced increases in serum $\mathrm{TxB}_{2}$ or 6-keto-PGF $\mathrm{PG}_{1 \alpha}$ at 1,2 , and $4 \mathrm{~h}$. Serum $\mathrm{TxB}_{2}$ and 6-keto-PGF ${ }_{1 \alpha}$ levels were $<10 \mathrm{pg} / 0.1 \mathrm{~mL}$ at all time points for these two groups of piglets.

Tumor necrosis factor. Figure 4 depicts changes in serum $\mathrm{TNF}_{\alpha}$ polypeptide levels in each group of piglets. INDO pretreatment did not significantly reduce GBS-induced serum $\mathrm{TNF}_{\alpha}$ polypeptide levels at 1,2 and $4 \mathrm{~h}$ in GBS+INDO compared with GBS alone piglets. PTF+INDO treatment attenuated GBSinduced serum $\mathrm{TNF}_{\alpha}$ polypeptide levels at both 2 and $4 \mathrm{~h}$ in GB+PTF+INDO compared with GBS alone piglets.

\section{DISCUSSION}

Pentoxifylline and indomethacin pretreatment of piglets infused with GBS caused significantly greater improvement in latephase pulmonary hemodynamic and gas exchange indices compared with piglets treated with INDO alone. PTF+INDO treatment of GBS sepsis in piglets also resulted in greater hemodynamic and gas exchange improvement compared with historical

Table 1. Systemic hemodynamics*

\begin{tabular}{lcccc}
\hline & PRE $\dagger$ & $1 \mathrm{~h}$ & $2 \mathrm{~h}$ & $4 \mathrm{~h}$ \\
\hline GO (L/min) & & & & \\
GBS & $0.93 \pm 0.07$ & $0.60 \pm 0.04 \ddagger$ & $0.58 \pm 0.04 \ddagger$ & $0.50 \pm 0.04 \ddagger$ \\
GBS + INDO & $0.85 \pm 0.11$ & $0.69 \pm 0.11 \ddagger$ & $0.60 \pm 0.07 \ddagger$ & $0.38 \pm 0.06 \ddagger$ \\
GBS + PTF + INDO & $0.87 \pm 0.07$ & $0.87 \pm 0.07 \S$ & $0.83 \pm 0.06 \S$ & $0.66 \pm 0.05 \ddagger \S$ \\
Pad $_{\text {(kPa) }}$ & & & \\
GBS & $10.9 \pm 0.4$ & $12.0 \pm 0.4$ & $12.4 \pm 0.5$ & $8.0 \pm 0.5 \ddagger$ \\
GBS + INDO & $11.7 \pm 0.7$ & $11.5 \pm 0.7$ & $11.9 \pm 0.9$ & $9.6 \pm 1.0$ \\
GBS + PTF + INDO & $10.5 \pm 0.3$ & $10.0 \pm 0.3$ & $9.8 \pm 0.4$ & $8.5 \pm 0.5 \ddagger$ \\
SVR (kPa/L/min) & & & \\
GBS & $11.7 \pm 1.0$ & $20.1 \pm 2.9 \ddagger$ & $21.5 \pm 4.5 \ddagger$ & $16.9 \pm 3.0 \ddagger$ \\
GBS + INDO & $13.7 \pm 3.2$ & $16.7 \pm 4.3$ & $19.9 \pm 2.0 \ddagger$ & $25.2 \pm 7.9 \ddagger$ \\
GBS + PTF + INDO & $12.0 \pm 1.9$ & $11.5 \pm 2.3 \S$ & $11.8 \pm 2.2 \S$ & $12.9 \pm 3.5$ \\
\hline
\end{tabular}

$*$ Values are expressed as mean \pm SEM. $1 \mathrm{~mm} \mathrm{Hg}=0.1333 \mathrm{kPa}$.

$\uparrow$ PRE, baseline value.

$\ddagger p<0.05$ compared with the intragroup PRE value.

$\S p<0.05$ compared with the same time point for the other two groups. 
Table 2. PVR/SVR ratios*

\begin{tabular}{lllll}
\hline & \multicolumn{1}{c}{ PRE $\uparrow$} & \multicolumn{1}{c}{$1 \mathrm{~h}$} & \multicolumn{1}{c}{$2 \mathrm{~h}$} & $4 \mathrm{~h}$ \\
\hline GBS & $0.131 \pm 0.006$ & $0.354 \pm 0.019 \ddagger \S$ & $0.326 \pm 0.010 \ddagger$ & $0.425 \pm 0.024 \ddagger$ \\
GBS + INDO & $0.125 \pm 0.007$ & $0.132 \pm 0.012$ & $0.210 \pm 0.031 \ddagger$ & $0.364 \pm 0.039 \ddagger$ \\
GBS + PTF + INDO & $0.142 \pm 0.008$ & $0.157 \pm 0.011$ & $0.161 \pm 0.009 \ddagger$ & $0.201 \pm 0.018 \pm \S$ \\
\hline *
\end{tabular}

$*$ Values are expressed as mean \pm SEM.

$\uparrow$ PRE, baseline.

$\ddagger p<0.05$ compared with the intragroup PRE value.

$\S p<0.05$ compared with the same time point for the other two groups.

Table 3. Gas exchange data*

\begin{tabular}{|c|c|c|c|c|}
\hline & $\mathrm{pH}$ & $\mathrm{PaCO}_{2}(\mathrm{kPa})$ & $\mathrm{PaO}_{2}(\mathrm{kPa})$ & $\mathrm{PvO}_{2}(\mathrm{kPa})$ \\
\hline \multicolumn{5}{|l|}{ GBS } \\
\hline PRE & $7.45 \pm 0.01$ & $5.2 \pm 0.1$ & $11.3 \pm 0.3$ & $5.1 \pm 0.1$ \\
\hline $1 \mathrm{~h}$ & $7.43 \pm 0.01$ & $5.5 \pm 0.3$ & $8.0 \pm 0.3 \dagger$ & $4.3 \pm 0.3 \dagger$ \\
\hline $2 \mathrm{~h}$ & $7.37 \pm 0.01 \dagger$ & $5.7 \pm 0.3$ & $7.3 \pm 0.4 \dagger$ & $4.0 \pm 0.3 \dagger$ \\
\hline $4 \mathrm{~h}$ & $7.30 \pm 0.02 \dagger$ & $5.7 \pm 0.3$ & $7.1 \pm 0.4 \dagger$ & $3.7 \pm 0.3 \dagger$ \\
\hline \multicolumn{5}{|c|}{ GBS + INDO } \\
\hline PRE & $7.45 \pm 0.02$ & $5.2 \pm 0.1$ & $11.1 \pm 0.3$ & $4.9 \pm 0.1$ \\
\hline $1 \mathrm{~h}$ & $7.47 \pm 0.01$ & $5.3 \pm 0.3$ & $10.9 \pm 0.3$ & $4.5 \pm 0.3$ \\
\hline $2 \mathrm{~h}$ & $7.45 \pm 0.02$ & $5.2 \pm 0.1$ & $10.8 \pm 0.4$ & $4.5 \pm 0.3$ \\
\hline $4 \mathrm{~h}$ & $7.37 \pm 0.03 \dagger$ & $5.5 \pm 0.3$ & $9.9 \pm 0.3 \dagger$ & $3.9 \pm 0.1 \dagger$ \\
\hline \multicolumn{5}{|c|}{ GBS + PTF + INDO } \\
\hline PRE & $7.45 \pm 0.01$ & $5.1 \pm 0.1$ & $11.7 \pm 0.4$ & $5.3 \pm 0.1$ \\
\hline $1 \mathrm{~h}$ & $7.46 \pm 0.02$ & $4.9 \pm 0.1$ & $12.0 \pm 0.4$ & $5.1 \pm 0.1$ \\
\hline $2 \mathrm{~h}$ & $7.45 \pm 0.01$ & $4.8 \pm 0.1$ & $11.6 \pm 0.5$ & $5.2 \pm 0.3$ \\
\hline $4 \mathrm{~h}$ & $7.40 \pm 0.02 \dagger$ & $4.9 \pm 0.1$ & $11.5 \pm 0.4 \ddagger$ & $5.1 \pm 0.3 \neq$ \\
\hline
\end{tabular}

*Values are expressed as mean \pm SEM. $1 \mathrm{~mm} \mathrm{Hg}=0.1333 \mathrm{kPa}$. $\mathrm{PaCO}_{2}$, arterial carbon dioxide pressure; $\mathrm{PvO}_{2}$, mixed venous oxygen pressure; PRE, baseline value.

$\dagger p<0.05$ compared with the intragroup PRE value.

$\ddagger p<0.05$ compared with the same time point for the other two groups.

controls treated with PTF alone (8). PTF+INDO and PTF pretreatment alone resulted in similar reductions in GBS-induced serum $\mathrm{TNF}_{\alpha}$ levels (8), but the combined treatment blocked GBS-induced thromboxane and prostacyclin production (8). PTF treatment of GBS sepsis caused augmentation of prostacyclin production (8). The inhibition of prostacyclin production by PTF+INDO may have improved both the late-phase gas exchange and hemodynamic responses compared with PTF treatment alone (8). In contrast to PTF+INDO treatment, INDO pretreatment alone did not significantly improve late-phase GBSinduced pulmonary hypertension, or late-phase decline in $\mathrm{CO}$. Our findings are similar to those of Runkle et al. (5) in which piglets were treated with INDO $(3 \mathrm{mg} / \mathrm{kg}) 15 \mathrm{~min}$ after the onset of the GBS infusion. INDO presumably has a beneficial effect in sepsis by inhibiting eicosanoid production. INDO does not affect endotoxin-induced TNF production in mice $(17,18)$ and did not significantly reduce GBS-induced TNF polypeptide levels in piglets. The beneficial effects of PTF+INDO pretreatment on GBS-induced late-phase features were greater than would be predicted from the effects of pretreatment with PTF or INDO alone. We speculate that the late phase of GBS sepsis in animal models is the most clinically relevant and the marked attenuation of the late-phase features by PTF+INDO is a new observation.

The presumed mechanisms for PTF+INDO treatment improving $\mathrm{PaO}_{2}$ values during GBS sepsis include 1 ) attenuating the decline in $\mathrm{CO}$ with resultant increases in mixed venous oxygen pressure (6) and 2) reducing ventilation-perfusion mismatching due to inhibition of vasoactive mediators (6). PTF+INDO treatment caused a greater reduction in PVR than SVR during both the acute and late phases of GBS sepsis. PTF causes preferential vasodilation of either the pulmonary or systemic vascular bed, depending upon which is the most constricted before treatment (36). We speculate that the preferential pulmonary vasodilation by PTF+INDO is due to the relatively
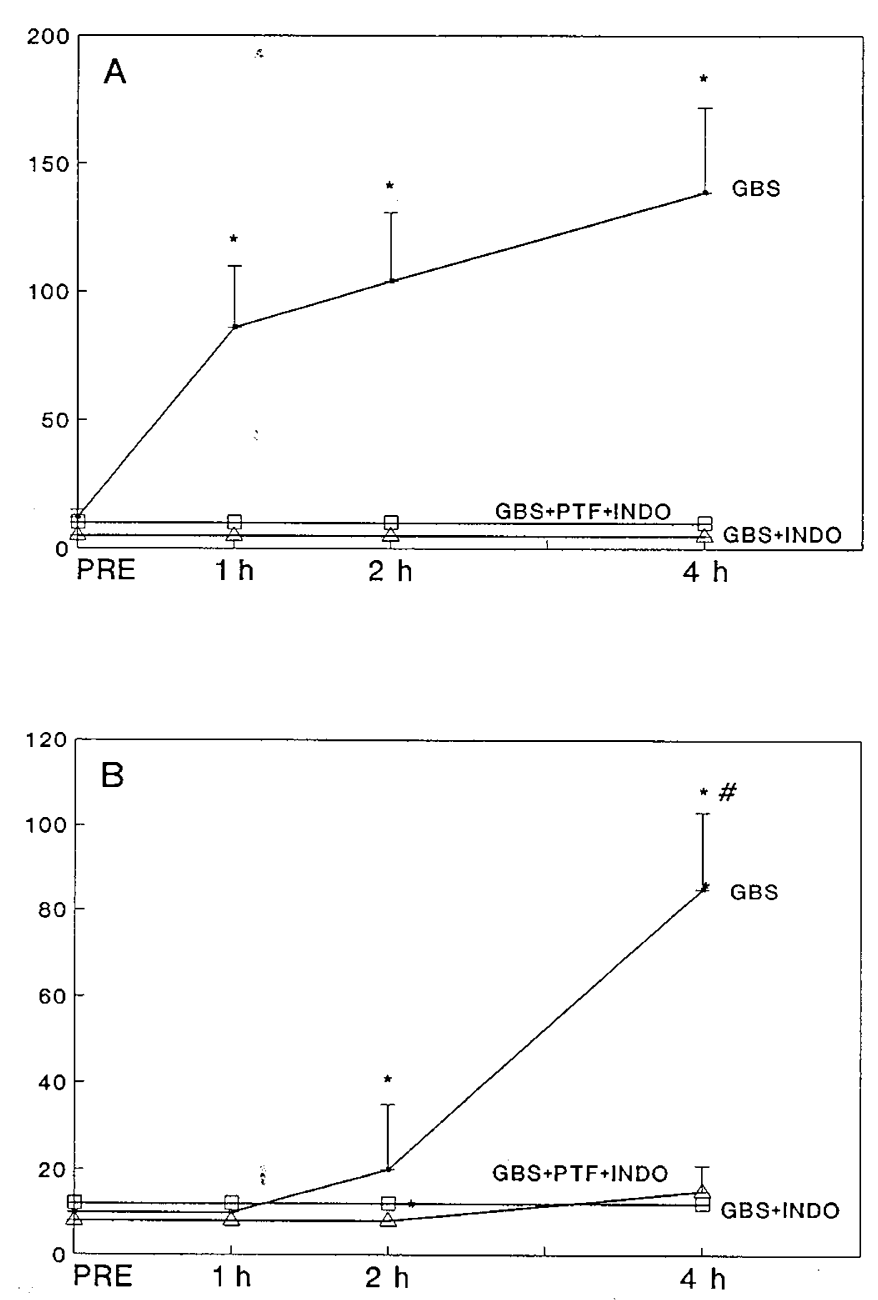

Fig. 3. PTF+INDO and INDO inhibit GBS-induced increases in $\mathrm{TxB}_{2}$ and 6-keto-PGF ${ }_{1 \alpha}$. Panel $A$, Serum $\mathrm{TxB}_{2}$ levels $(\mathrm{pg} / 0.1 \mathrm{~mL})$ are plotted versus time for the three groups of piglets. Panel B, Serum 6keto-PGF ${ }_{1 \alpha}$ levels $(\mathrm{pg} / 0.1 \mathrm{~mL})$ are plotted versus time for the three groups of piglets. Values are expressed as mean \pm SEM for both assays. * denotes $p<0.05$ compared with intragroup PRE value; \# denotes $p<$ 0.05 compared with the other two groups at the same time point.

greater GBS-induced increase in PVR compared with SVR. PTF+INDO prevented the GBS-induced fall in $\mathrm{CO}$ at 1 and $2 \mathrm{~h}$ by attenuating the decline in stroke volume (data not shown); however, PTF+INDO did not prevent the decline in $\mathrm{P}_{\mathrm{sa}}$ at $4 \mathrm{~h}$ and only attenuated the reduction in $\mathrm{CO}$ and stroke volume (data not shown) at $4 \mathrm{~h}$. The three groups of piglets showed a similar degree of tachycardia at $4 \mathrm{~h}$ of GBS infusion (data not shown). The fall in $\mathrm{CO}$ at $4 \mathrm{~h}$ may in part reflect the untoward vasodilatory properties of PTF at a dose of $20 \mathrm{mg} / \mathrm{kg} / \mathrm{h}$ or potential negative inotropic effects of GBS. However, PTF infusion $(20 \mathrm{mg} / \mathrm{kg} / \mathrm{h})$ into control piglets caused no fall in $\mathrm{CO}$ or $\mathrm{P}_{\mathrm{sa}}(8)$.

Vasoactive arachidonic acid metabolites are important mediators in models of gram-negative and GBS sepsis $(4-9,19-21)$ 


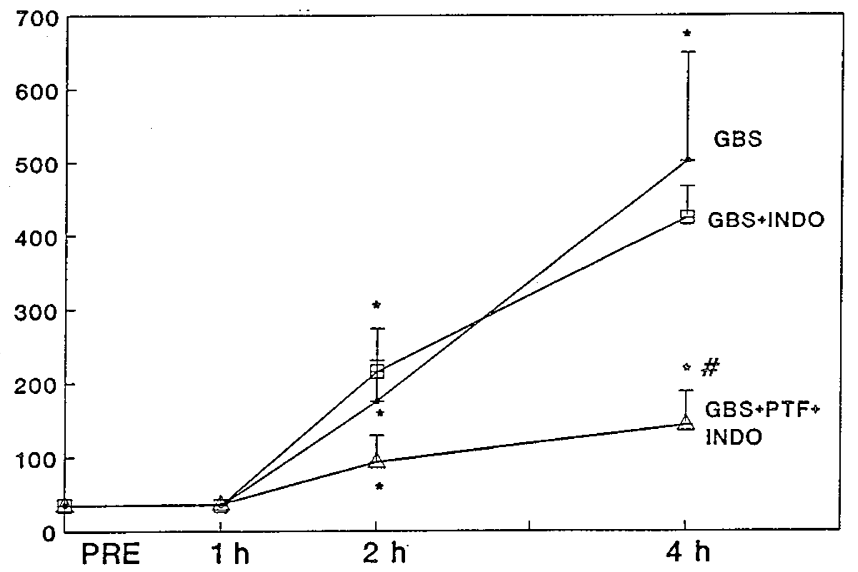

Fig. 4. PTF+INDO attenuates GBS-induced $\mathrm{TNF}_{\alpha}$ production. Serum $T N F_{\alpha}$ polypeptide levels $(\mathrm{pg} / \mathrm{mL})$ are plotted versus time for the three groups of piglets. Values are expressed as mean \pm SEM. $*$ denotes $p<0.05$ compared with the intragroup PRE value; \# denotes $p<0.05$ compared with the other two groups at the same time point.

and in some models of $\mathrm{TNF}_{\alpha}$-induced shock $(22,23)$. INDO, ibuprofen, and combined lipoxygenase and cyclooxygenase inhibitors ameliorate endotoxin-induced shock $(17,18,21)$. INDO treatment blocks the GBS-induced late-phase decline in $\mathrm{P}_{\mathrm{sa}}$, but not late-phase GBS-induced pulmonary hypertension (5). Dazmegrel, a thromboxane synthase inhibitor, reverses GBS-induced pulmonary hypertension up to $2 \mathrm{~h}$ after the onset of infusion, but was not tested at $4 \mathrm{~h}$ into GBS infusion when there were greater increases in serum $\mathrm{TNF}_{\alpha}$ levels (9). There are discrepant reports on the effect of these drugs on the attenuation of $\mathrm{TNF}_{\alpha^{-}}$ induced shock $(18,23,24)$. Some investigators report that INDO only attenuates endotoxin effects and has no influence on combined endotoxin- and $\mathrm{TNF}_{\alpha}$-induced shock (24). There is less information available on the role of eicosanoids in $\mathrm{TNF}_{\alpha}$-induced pulmonary hypertension $(22,25)$. Recombinant human- $\mathrm{TNF}_{\alpha}$ infusion in piglets induced sustained pulmonary hypertension; pretreatment with dazmegrel inhibited the rise in $\mathrm{P}_{\mathrm{pa}}$ up to 30 min after the onset of $\mathrm{TNF}_{\alpha}$ infusion, but did not blunt a later phase of $\mathrm{TNF}_{\alpha}$-induced pulmonary hypertension (25). Bacterialor $\mathrm{TNF}_{\alpha}$-induced eicosanoids are important mediators of the hemodynamic and gas exchange abnormalities of sepsis, but inhibition of arachidonic acid metabolities alone is not sufficient to attenuate all the effects of $\mathrm{TNF}_{\alpha}$ or sepsis.

$\mathrm{TNF}_{\alpha}$ is an important mediator of gram-negative and grampositive septic shock $(8,10,22,26-28)$. Pretreatment with anti$\mathrm{TNF}_{\alpha}$ antibody prevented septic shock in a primate model of lethal gram-negative bacteremia (26); inhibition of serum $\mathrm{TNF}_{\alpha}$ production by pentoxifylline significantly improved survival in a murine model of endotoxic shock (15). However, in a model of gram-negative pneumonia, anti-TNF $\mathrm{F}_{\alpha}$ antibody neutralized lung lavage $\mathrm{TNF}_{\alpha}$ levels and blunted pulmonary antibacterial defenses (29). Therefore, although the attenuation of the systemic $\mathrm{TNF}_{\alpha}$ response may be beneficial, altering local $\mathrm{TNF}_{\alpha}$ production at inflammatory sites may have some deleterious effects $(29,30)$. However, other studies suggest that $\mathrm{TNF}_{\alpha}$ alone cannot mimic the features of septic shock (24). TNF ${ }_{\alpha}$ may need to interact with bacterial products or other vasoactive mediators to cause untoward effects $(17,22-24,31,32) . \mathrm{TNF}_{\alpha}$ can act synergistically with IL-1 (31) or with gram-negative or gram-positive bacterial products in the induction of shock in animal models $(24,32)$. There is no direct evidence that $\mathrm{TNF}_{\alpha}$ and eicosanoids act synergistically in the pathophysiology of sepsis, but this possibility seems reasonable based on our observations that PTF+INDO pretreatment caused marked attenuation of GBS-induced late features compared with the modest effects of INDO or PTF alone (8).

The production and/or activity of $\mathrm{TNF}_{\alpha}$ and arachidonic acid metabolites is interrelated in adult animal models of sepsis (17, $18,22,23,25,31)$. TNF $\alpha$ infusion can induce the synthesis of $\mathrm{TxA}_{2}, \mathrm{PGI}_{2}, \mathrm{PGE}_{2}$, and leukotrienes $(22,27)$; leukotriene $\mathrm{B}_{4}$ can augment alveolar macrophage production of $\mathrm{TNF}_{\alpha}$ in vitro (33). Inhibition of thromboxane and prostaglandin production by ibuprofen or indomethacin ameliorates endotoxin- and $\mathrm{TNF}_{\alpha^{-}}$ induced shock and lung injury in some adult animal models (17, $21,23,31$ ). In addition, dual inhibition of both cyclooxygenase and 5-lipoxygenase markedly attenuates serum $\mathrm{TNF}_{\alpha}$ levels and lethality in a murine model of endotoxic shock (18). These observations also support the speculation for an additive or synergistic interaction between $\mathrm{TNF}_{\alpha}$ and arachidonic acid metabolites.

Serum $\mathrm{TNF}_{\alpha}$ polypeptide levels may overestimate in vivo $\mathrm{TNF}_{\alpha}$ bioactivity in piglets treated with PTF+INDO. GBS infusion in piglets induces $T \mathrm{TNF}_{\alpha}$ bioactivity as assayed by the L-929 cytotoxicity assay (8). Piglets infused with GBS+PTF+INDO had significant attenuation of serum $\mathrm{TNF}_{\alpha}$ polypeptide levels at $4 \mathrm{~h}$ compared with GBS alone piglets, but it is uncertain how much residual $\mathrm{TNF}_{\alpha}$ bioactivity remained. To measure in vivo $\mathrm{TNF}_{\alpha}$ bioactivity, serum $\mathrm{TNF}_{\alpha}$ bioassays would need to be done in vitro at the same concentrations of PTF present in the plasma of treated piglets, and these were not performed in this study. PTF inhibits $\mathrm{TNF}_{\alpha}$ production in vitro by $50 \%$ at a concentration of $5 \mu \mathrm{M}(10)$, but it required approximately 100 -fold greater PTF concentrations to inhibit $\mathrm{TNF}_{\alpha}$-induced L-929 cytotoxicity (11). PTF blood levels have not been reported in animal models of sepsis, and the PTF concentration necessary to inhibit $\mathrm{TNF}_{\alpha^{-}}$ induced cardiopulmonary responses is uncertain. We speculate that PTF inhibits serum $\mathrm{TNF}_{\alpha}$ bioactivity in the GBS+PTF+INDO group to a greater degree than suggested by the serum $\mathrm{TNF}_{\alpha}$ polypeptide levels $(11,15)$, and this could partially explain the beneficial effects of PTF treatment of GBS sepsis.

The beneficial effects of PTF+INDO treatment in the piglet model of GBS sepsis may be due to factors other than the inhibition of thromboxane, prostacyclin, and $\mathrm{TNF}_{\alpha}$. PTF attenuates $\mathrm{TNF}_{\alpha}$ production and $\mathrm{TNF}_{\alpha}$-induced lung injury $(8,10-$ 15 ), but has multiple additional effects in adult animals that could improve the untoward effects of GBS sepsis. These include 1) decreased sepsis-induced lung injury $(12), 2)$ attenuation of $\mathrm{TNF}_{\alpha^{-}}$and endotoxin-induced endothelial cell injury in vitro $(34,35), 3)$ decreased neutrophil sequestration in the lung $(13)$, 4) vasodilatory properties, including the attenuation of hypoxic pulmonary vasoconstriction $(36,37)$, and 5) reduced blood viscosity (37). It is uncertain if all of these PTF effects are due to the inhibition of $\mathrm{TNF}_{\alpha}$. There are no published reports on the effect of PTF treatment on either TNF $\alpha^{-}$or TxA $\mathrm{T}_{2}$-induced pulmonary vasoconstriction. However, preliminary data from our laboratory show that PTF attenuates acute $(<30 \mathrm{~min})$ pulmonary hypertension in piglets infused with human recombinant $\mathrm{TNF}_{\alpha}$ (38). INDO inhibits thromboxane and prostaglandin synthesis by inhibition of cyclooxygenase, but in some species, or at high concentrations, also inhibits phospholipase $\mathrm{A}_{2}$, the initial enzymatic step in eicosanoid metabolism (39). Additional eicosanoids, such as leukotrienes, not measured in this study, but potentially inhibited by INDO, may contribute to the untoward effects of GBS sepsis. There are indirect data that leukotrienes are not important in the acute phase of GBS sepsis (20), but there are no data on the role of leukotrienes in the late phase of GBS sepsis. Finally, GBS sepsis probably stimulates additional proinflammatory and vasoactive mediators, not measured in this study, that may be inhibited by PTF or INDO treatment. For example, GBS induces the production of additional cytokines in vitro, such as IL-1- $\beta$ (40), which if induced in vivo could act synergistically with $\mathrm{TNF}_{\alpha}$ to cause hemodynamic alterations and lung injury (31). GBS may also cause hypoxemia and pulmonary hypertension by granulocyte- or complement-mediated pulmonary vascular injury $(41,42)$, or GBS toxins may act alone or synergistically with proinflammatory mediators to cause unto- 
ward effects (43). PTF and/or INDO may ameliorate these potential GBS-induced effects in addition to inhibiting the vasoactive mediators tested in this study.

We conclude that in this piglet model of GBS sepsis, combined PTF+INDO pretreatment is superior to INDO or PTF pretreatment alone in improving the hemodynamic and gas exchange alterations. This beneficial effect of combined PTF+INDO is in part due to inhibition of thromboxane, prostacyclin, and $\mathrm{TNF}_{\alpha}$ production and presumably attenuation of in vivo $\mathrm{TNF}_{\alpha}$ activity. Inhibition of both serum eicosanoid and $\mathrm{TNF}_{\alpha}$ production may provide adjunctive therapy for human newborns with sepsis and pulmonary hypertension.

Acknowledgments. The authors thank James Jordan, Richard Tuck, Sue Palmer, and Dong Nguyen for their technical assistance.

\section{REFERENCES}

1. Baker CJ 1977 Summary of the workshop on perinatal infection due to group B streptococcus. J Infect Dis 136:137-151

2. Hammerman C, Lass N, Strates E, Komar K, Bui KC 1987 Prostanoids in neonates with persistent pulmonary hypertension. J Pediatr 110:470-472

3. Shankaran S, Farooki ZQ, Desai R $1982 \beta$-hemolytic streptococcal infection appearing as persistent fetal circulation. Am J Dis Child 136:725-727

4. Rojas J, Green RS, Hellerqvist CG, Olegard R, Brigham KL, Stahlman MT 1981 Studies on group B $\beta$-hemolytic streptococcus. II. Effects on pulmonary hemodynamics and vascular permeability in unanesthetized sheep. Pediatr Res 15:899-904

5. Runkle B, Goldberg RN, Streitfeld MM, Clark MR, Buron E, Setzer ES, Bancalari E 1984 Cardiovascular changes in group B streptococcal sepsis in the piglet: response to indomethacin and the relationship to prostacyclin and thromboxane $\mathrm{A}_{2}$. Pediatr Res 18:874-878

6. Truog WE, Sorensen GK, Standaert TA, Redding GJ 1986 Effects of the thromboxane synthase inhibitor, dazmegrel (UK 38,485 ) on pulmonary gas exchange and hemodynamics in neonatal sepsis. Pediatr Res 20:481-486

7. Pauly TH, Bowdy BD, Haven CA, Barr SB, Gillespie MN 1988 Evidence for hydroxyl radical involvement in group B streptococcus-induced pulmonary hypertension and arterial hypoxemia in young piglets. Pediatr Res 24:735739

8. Gibson RL, Redding GJ, Henderson WR, Truog WE 1991 Group B streptococcus induces tumor necrosis factor in neonatal piglets: effect of the TNF inhibitor, pentoxifylline, on hemodynamics and gas exchange. Am Rev Respir Dis 143:598-604

9. Truog WE, Gibson RL, Juul SE, Henderson WR, Redding GJ 1988 Neonatal group B streptococcal sepsis: effects of late treatment with dazmegrel. Pediatr Res 23:352-356

10. Strieter RM, Remick DG, Ward PA, Spengler RN, Lynch III JP, Larrick J, Kunkel S 1988 Cellular and molecular regulation of tumor necrosis factoralpha production by pentoxifylline. Biochem Biophys Res Commun $155 ; 1230-1236$

11. Lilly CM, Sandhu JS, Ishizaka A, Harada H, Yonemaru M, Larrick JW, Shi T-X, O'Hanley PT, Raffin TA 1989 Pentoxifylline prevents tumor necrosis factor-induced lung injury. Am Rev Respir Dis 139:1361-1368

12. Ishizaka A, Wu Z, Stephens KE, Harada H, Hogue RS, O'Hanley PT, Raffin TA 1988 Attenuation of acute lung injury in septic guinea pigs by pentoxifylline. Am Rev Respir Dis 138:376-382

13. Welsh CH, Lien D, Worthen GS, Weil JV 1988 Pentoxifylline decreases endotoxin-induced pulmonary neutrophil sequestration and extravascular protein accumulation in the dog. Am Rev Respir Dis 138:1 106-1114

14. Zabel P, Schonharting MM, Wolter DT, Schade UF 1989 Oxpentifylline in endotoxemia. Lancet 2:1474-1477

15. Schade UF 1990 Pentoxifylline increases survival in murine endotoxin shock and decreases formation of tumor necrosis factor. Circ Shock 31:171-181

16. Gibson RL, Redding GJ, Truog WE, Henderson WR, Rubens CE 1989 Isogenic group B streptococci devoid of capsular polysaccharide or $\beta$-hemolysin: pulmonary hemodynamic and gas exchange effects during bacteremia in piglets. Pediatr Res 26;241-245

17. Ha DK, Cheng CP, Fung KP Choy YM, Lee CY 1987 Effect of antiinflammatory drugs on the production of tumor necrosis factor and lipopolysaccharide-induced mortality in mice. Cancer Lett 34:291-296

18. Badger AM, Olivera D, Talmadge JE, Hanna N 1989 Protective effect of SK\&F 86002 , a novel dual inhibitor of arachidonic acid metabolism, in murine models of endotoxin shock: inhibition of tumor necrosis factor as a possible mechanism of action. Circ Shock 27:51-61
19. Pinheiro JMB, Pitt BR, Gillis CN 1989 Roles of platelet-activating factor and thromboxane in group B streptococcus-induced pulmonary hypertension in piglets. Pediatr Res 26:420-424

20. Siguihara C, Goldberg RN, Hehre D, Bancalari A, Bancalari E 1987 Effect of cyclooxygenase and lipoxygenase products on pulmonary function in group B streptococcal sepsis. Pediatr Res 22:478-482

21. Brigham KL, Meyrick B 1986 Endotoxin and lung injury. Am Rev Respir Dis 133:913-927

22. Johnson J, Meyrick B, Jesmok G, Brigham KL 1989 Human recombinant tumor necrosis factor alpha infusion mimics endotoxemia in awake sheep. $J$ Appl Physiol 66:1448-1454

23. Kettelhut IC, Fiers W, Goldberg AL 1987 The toxic effects of tumor necrosis factor in vivo and their prevention by cyclooxygenase inhibitors. Proc Natl Acad Sci USA 84:4273-4277

24. Myers AK, Robey JW, Price RM 1990 Relationship between tumour necrosis factor, eicosanoids and platelet-activating factor as mediators of endotoxininduced shock in mice. Br J Pharmacol 99:499-502

25. Truog WE, Gibson RL, Henderson WR, Redding GJ 1990 Tumor necrosis factor-induced neonatal pulmonary hypertension: effects of dazmegrel pretreatment. Pediatr Res 27:466-471

26. Tracey KJ, Fong Y, Hesse DG, Manogue KR, Lee AT, Kuo GC, Lowry SF, Cerami A 1987 Anti-cachectin/TNF monoclonal antibodies prevent septic shock during lethal bacteremia. Nature 330:662-664

27. Beutler BA 1989 Orchestration of septic shock by cytokines: the role of cachectin (tumor necrosis factor). Prog Clin Biol Res 286:219-235

28. Marks JD, Marks CB, Luce JM, Montgomery AB, Turner J, Metz CA, Murray JF 1990 Plasma tumor necrosis factor in patients with septic shock. Am Rev Respir Dis 141:94-97

29. Nelson S, Bagby G, Summer W 1991 Anti-tumor necrosis-alpha antibody suppresses pulmonary antibacterial defenses. Am Rev Respir Dis 143:A393(abstr)

30. Tracey KJ, Vlassara H, Cerami A 1989 Cachectin/tumor necrosis factor. Lancet 1:1122-1125

31. Okusawa S, Gelfand JA, Ikejima T, Connolly RJ, Dinarello CA 1988 Interleukin- 1 induces a shock-like state in rabbits: synergism with tumor necrosis factor and the effect of cyclooxygenase inhibition. J Clin Invest 81:11621172

32. Rothstein JL, Schreiber H 1988 Synergy between tumor necrosis factor and bacterial products causes hemorrhagic necrosis and lethal shock in normal mice. Proc Natl Acad Sci USA 85:607-611

33. Dubois CM, Bissonnette E, Rola-Pleszczynski M 1989 Asbestos fibers and silica particles stimulate rat alveolar macrophages to release tumor necrosis factor: autoregulatory role of leukotriene $B_{4}$. Am Rev Respir Dis 139:12571264

34. Zheng $\mathrm{H}$, Crowley JJ, Chan $\mathrm{JC}$, Hoffman $\mathrm{H}$, Hatherill JR, Ishizaka A, Raffin TA 1990 Attenuation of tumor necrosis factor-induced endothelial cell cytotoxicity and neutrophil chemiluminescence. Am Rev Respir Dis 142:1073-1078

35. Sato K, Stelzner TJ, O'Brien RF, Weil JV, Welsh CH 1991 Pentoxifylline lessens the endotoxin-induced increase in albumin clearance across pulmonary artery endothelial monolayers with and without neutrophils. Am J Respir Cell Mol Biol 4:219-227

36. Hakim TS, Patrella J 1988 Attenuation of pulmonary and systemic vasoconstriction with pentoxifylline and aminophylline. Can J Physiol Pharmacol 66:396-401

37. Chick TW, Scotto P, Icenogle MV, Sikes CW, Doyle MP, Riedel CE, Wood SC, Loeppky JA 1988 Effects of pentoxifylline on pulmonary hemodynamics during acute hypoxia in anesthetized dogs. Am Rev Respir Dis 137:10991103

38. Truog WE, Redding GJ, Standaert TA, Gibson RL 1990 Effect of pentoxifylline on tumor necrosis factor-induced pulmonary hypertension in piglets. FASEB J 4:A573(abstr)

39. Kaplan L, Weiss J, Elsbach P 1978 Low concentrations of indomethacin inhibit phospholipase $\mathrm{A}_{2}$ of rabbit polymorphonuclear leukocytes. Proc Natl Acad Sci USA 75:2955-2958

40. Glover DM, Brownstein D, Burchett SB, Larsen A, Wilson CB 1987 Expression of HLA class II antigens and secretion of interleukin-1 by monocytes and macrophages from adults and neonates. Immunology 61:195-201

41. Engelhardt B, Sandberg K, Bratton D, van den Abbeele A, Grogaard J, Hellerqvist C, Sundell H 1987 The role of granulocytes in the pulmonary response to group B streptococcal toxin in young lambs. Pediatr Res 21:159165

42. McFall TL, Zimmerman GA, Augustine NH, Hill HR 1987 Effect of group B streptococcal type-specific antigen on polymorphonuclear leukocyte function and polymorphonuclear leukocyte-endothelial cell interaction. Pediatr Res 21:517-523

43. Hellerqvist CG, Sundell H, Gettins P 1987 Molecular basis for group B $\beta$ hemolytic streptococcal disease. Proc Natl Acad Sci USA 84:51-55 